\title{
Logic as (Normative) Inference Theory: \\ Formal vs. Non-formal Theories \\ of Inference Goodness
}

\author{
LILIAN BERMEJO LUQUE
}

Spanish Open University, UNED

Department of Logic and of History and Philosophy of Science

Edificio de Humanidades, Senda del Rey, 7

28040-Madrid

Spain

\section{lilianbl@fsof.uned.es}

\begin{abstract}
I defend a conception of Logic as normative for the sort of activities in which inferences supervene, namely, reasoning and arguing. Toulmin's criticism of formal logic will be our framework to shape the idea that in order to make sense of Logic as normative, we should conceive it as a discipline devoted to the layout of arguments, understood as the representations of the semantic, truth relevant, properties of the inferences that we make in arguing and reasoning.
\end{abstract}

Résumé: Je défends une conception normative de la logique appliquée aux inférences, notamment aux raisonnements et aux arguments. La critique avancée par Toulmin de la logique formelle sera notre fondement pour façonner l'idée qu’une logique normative doit se concevoir comme une discipline consacrée à décrire et à expliciter des arguments, compris comme des représentations véridiques et sémantiques des inférences que nous faisons dans des arguments et dans des raisonnements

Keywords: formal/informal logic, inference, normative theory of inference, Toulmin's model of argument.

\section{Introduction}

The main goal of this paper is to defend a conception of Logic as a normative discipline regarding inferences, i.e., a discipline devoted to developing criteria for determining inference goodness, and consequently, devoted to enabling certain types of appraisal of the activities in which inferences supervene, namely, arguing and reasoning. I agree with most argumentation theorists that argumentation goodness is not to be determined by Logic alone. That is, I do not take logical normativity to be argumentative normativity tout court. But I hold that there is a logical dimension 
of argumentation, related to its semantic properties, which is part of what we have to evaluate in order to decide on argumentative goodness.

On the other hand, in order to enable such a conception of Logic as normative for reasoning and arguing, I will have to address the question of its formality. Thus, there is a second goal in this paper, which is to show that the logical goodness of argumentation and reasoning is not to be determined by formal models. For this goal, I am going to adopt, to a great extent, Toulmin's theses in The Uses of Argument (1958).

In a few words, the problem I am going to deal with is the following. Logic is usually seen as an (indefinite) set of complementary theories for determining inference goodness. An argument is valid, it is said, if it has a valid logical form, that is, if there is a formal system for which it is valid. On this perspective, logical normativity would be a matter of the sort of coherence with certain axioms that only a formal system, as a set of axioms and rules of inference, may provide. But given the existence of alternative models (i.e., models that are incompatible at some point), such normativity regarding what we can or cannot infer seems far from obvious. For example, why can we infer that $p$, given that it is not the case that not-p? Certainly, classical theories would convey that this inference is correct, according to the most usual formalization of "it is not the case that" and "not-". But intuitionists, for example, would refrain from granting such an inference. On the face of it, we usually say that intuitionist and classical logicians endorse different conceptions of negation. Likewise, for example, alternative systems of deontic logic would have been developed in order to grasp different conceptions of deontic terms, just as alternative systems of temporal logic would sanction different conceptions of time, past, present and futureand so on for other "logics". Consequently, logical normativity would seem to depend, at its best, on criteria that fall outside of the scope of the very discipline, namely, criteria to determine whether a particular inference should be appraised according to one formal system or another. My goal is to avoid this problem by proposing a conception of logical normativity as a matter of the constitutive pragmatic conditions of the type of acts in which inferences supervene, namely the acts of arguing and reasoning. Logic, so conceived, would be a discipline constituted by different theories to properly enable, in Toulmin's words, the "layout of arguments".

The term 'logic' has different meanings. For my part, I would like to distinguish the discipline 'Logic' (with a capital 'L') from:

(1) a logical theory, i.e., a particular model, or set of models, to tell sound from unsound inferences-like, 
for example, classical first-order logic, deontic logic, fuzzy logic, etc. ${ }^{1}$

(2) the logic of a piece of argumentation or reasoningthat is, what we may call its 'inferential structure';

(3) 'logic', as the logical dimension of argumentation and reasoning, i.e., the sort of features that a normative theory of inference can appraise.

Thus, in a nutshell, my aim is to show that if we adopt a conception of logic like the one Toulmin would be defending in The Uses of Argument, and develop our normative models according to it, the above problem of the normativity of Logic vanishes.

As we are going to see, the main feature of Toulmin's conception of logic is its non-formality. According to the above distinctions, the question of whether logic is formal or informal will be discussed as the question of whether argumentation and reasoning are to be logically appraised by formal or informal theories. I am going to adopt Toulmin's criticism of the formal approach to Logic in order to state the conditions for thinking of this discipline as normative for reasoning and arguing. Yet, I will also propose some modifications and clarifications to better suit our goal.

\section{Logical possibilities, impossibilities and necessities}

One of the key elements of The Uses of Argument (1958) is a pragmatic account of the qualifiers by means of which we put forward our assertions-and also our beliefs. ${ }^{2}$ Toulmin starts by analyzing the role of 'cannot', a modal term that, in his view, has not received much attention. He observes that there are different situations in which we can properly use this term, either for establishing impossibilities (physical, mathematical, etc.) or improprieties (linguistic, moral, etc.). Yet, they all would have a common pattern: "P being what it is, you must rule out anything involving Q: to do otherwise would be $\mathrm{R}$ and would invite $\mathrm{S}$ ” (1958: 29).

\footnotetext{
${ }^{1}$ On this account, Toulmin's model of argument would be one of these theories for inference appraisal.

${ }^{2}$ In The Uses of Argument, Toulmin does not take into account the inferences that we make in reasoning, but I am going to assume that his proposals are easily extended to them. This is important to our goal of making sense of Toulmin's model of argument as endorsing the pragmatic constitutive conditions of inferences, i.e., the normative conditions that acts of reasoning and acts of arguing have in common.
} 


\section{Lillian Bermejo Luque}

Taking this pattern into account, Toulmin distinguishes two aspects of the meaning of qualifiers, namely, their force and their criteria of use. The force of a qualifier would correspond to the practical implications of its use (1958: 30), and it would be fieldinvariant. For example, whenever we say that something is 'possible' we are pragmatically meaning that it is worth considering. For their part, the criteria of a qualifier would be “(...) the reasons by reference to which we decide in any context that the use of a particular modal term is appropriate” (1958: 30). In Toulmin's view, these criteria determine the meaning of qualifiers as much as the pragmatic consequences of their use, for they enable, in turn, another sort of qualification: when we put forward a proposition on believing or asserting it, we do it so with a certain force. In this sense, to believe or to assert would be to state the truth, possibility, degree of probability, etc., of a given proposition. Yet, the credentials that make it rational to believe that $p^{3}$, or that support our assertion that $p$, qualify our belief or assertion that $p$ by making salient that $p$ is, for example, physically, aesthetically, morally, pragmatically, legally, economically, linguistically, logically, etc., impossible, possible, necessary, probable, true, etc. In this sense, the criteria for the use of qualifiers would be fielddependent.

Now, when we infer, we not only put forward the reasons that we have for our conclusions, but also the conclusions themselves. Moreover, it is because we believe or implicitly assert that there is a link between our reason and our conclusion that our mere putting forward a proposition counts as a reason for our conclusion. Otherwise, our believing/asserting that $p$ and then coming to believe/assert that $q$ would not count as reasoning or arguing, but as something like an association of ideas, or a merely saying that $p$ and also, that $q$. This link between reason and conclusion Toulmin calls the warrant of the argument.

In Bermejo-Luque (2006), I have argued for an account of the warrant of an argument as the associated conditional whose antecedent is the reason of the argument, and whose consequence is its conclusion ${ }^{4}$. Warrants would be implicit conditional statements

\footnotetext{
${ }^{3}$ Actually, I would say "that turn the mere entertaining-that-p into a fullfledged belief that $p$ ”.

${ }^{4}$ In that paper, I proposed an interpretation of this conditional as the material conditional, which is something that, as D. Hitchcock (2007) has criticised, is open to apparent paradoxes. I have defended myself from this criticism in Bermejo-Luque (2007), where I appealed to Grice's distinction between the semantics and the pragmatics of conditionals.

Remarkably, on this account, the evaluation of warrants would be on a par with the evaluation of reasons: not only because, in certain cases, reasons may be conditional claims, but above all because, as Brandom (1994) insists, conceptual contents amount to inference licenses, and vice
} 
that, in being sound, would authorize the inference from reason to conclusion. Because they are statements, they may be qualified with as many types of qualifiers as any other statement. And it would be, precisely, the qualifier that correspond to the warrant of our argument that would entitle us to draw our conclusions "necessarily”, “probably”, "tentatively”, "possibly”, etc. On this account, the validity of an argument would be a matter of the correctness of its warrant, and a good argument would be an argument whose conclusion has been properly qualified, given the qualifiers that actually correspond to its reason and warrant ${ }^{5}$.

Constrastingly, as Toulmin complains, the concept of argumentative validity underlying formal theories of inference is that of analytic validity, because their criteria for the use of qualifiers like 'possible', 'impossible' or 'necessary' are equivalent to criteria for the use of terms like 'consistent', 'inconsistent' and 'the negation of which being inconsistent'. However, on his view, these criteria only serve to establish the "preliminary formalities of argument-stating, (and) not (with) the actual merits of any argument” (1958: 173). Formal theories aim at establishing relations of consistency and contradiction among propositions. But on Toulmin's view, that certain propositions do not contradict each other is nothing but a mere preliminary of argument evaluation. For the logical possibility of a conclusion, i.e., the consistency of all the argument's propositions, would not even be "a prima facie case" (1958: 172) in favor of a claim; rather, it would be just a minimum of any discourse, a prerequisite of meaningfulness.

Analogously, a logical impossibility would just preclude any judgment on the value of an argument. It would be equivalent to meaninglessness: it is only once we have determined the

versa. That includes, for example, moral and aesthetic contents, so that, in principle, this account would be suitable for the appraisal of moral and aesthetic argumentation and reasoning.

${ }^{5}$ We must take into account that, in The Uses of Argument, Toulmin does not directly addresses the question of the evaluation of argumentation; he just offers the guidelines that can be derived from his ideas on probability and his conceptions of validity and justification. According to them, many authors have assumed that Toulmin would seem to propose two sorts of standards for the appraisal of argumentation: field-dependent and field-invariant standards. But this idea is just outlined in The Uses of Argument, and, as I have tried to show in Bermejo-Luque (2006) there are good reasons to be cautious with the view that field-dependent and field-invariant standards are standards for argumentation appraisal rather than criteria for the use of qualifiers.

In a forthcomming paper, I develop this proposal of argument evaluation. I consider, for example, empirical tests for mathematical conjectures as arguments whose conclusions are necessary propositions, yet advanced by qualifiers like "probably". 
intelligibility of an argument that we may be able to determine the possibility, impossibility or necessity of a claim, given the reasons that we adduce for it. In Toulmin's words, "nothing is decided by merely putting a case in proper form, but rather a situation is created in which we can begin to ask rational questions: we are put into a position in which we can use substantial decisionprocedures" (1958: 172).

Finally, regarding logical necessity, we may say that, in a certain way, Toulmin's main goal in The Uses of Argument is to show that the formal validity of an argument does not tell us anything about its goodness. As he will argue, formal validity is, rather, just a way of "phrasing" arguments. On this view, formal theories' criteria for validity would rest exclusively on language as syntax, particularly, on the possibility of obtaining entailment relationships by formalizing the propositions involved. Formal logicians have taken this concept of validity as paradigmatic to decide on the value of arguments. And, for Toulmin, the question is: how linguistic conventions might suffice to determine the acceptability of our claims? In his view, the problem for formal theories to become normative is that "systematic necessities serve not to impose but only to express conceptual truths, and they can do so only for so long as we do not modify our working concepts in some vital respect” (1958: 207).

According to Toulmin, the goal of formal theories is to produce systems of field-invariant criteria to appraise arguments. In principle, there is nothing intrinsically wrong with this ambition. But he considers that it misses its point. Toulmin criticizes formal logicians for having assumed that formal validity is the ultimate form of argument validity. As we have seen, this view would be, in turn, a consequence of the assumption that the only way to determine possibility, impossibility and necessity is by appealing to certain linguistic criteria, so as to refuse other types of necessity, possibility and impossibility like causal, moral, legal, pragmatic, etc. As a consequence, Toulmin observes, formal theories are forced to admit as possible any conclusion not contradicting the premises, turning out "the rational elimination of possibilities (...) infinitely more difficult" (1958: 152).

Contrastingly, Toulmin insists that the validity of an argument is inextricably linked to the forcefulness of the reasons that we have for its conclusion. And the goal here will be to show that this is by no means a formal or an analytic matter, but a matter of the substantial acceptability of the warrant that is meant to license the step from the reasons adduced to the conclusion drawn in the act of reasoning or arguing. To this end, it will be important to defend Toulmin's following three distinctions.

First, Toulmin distinguishes between necessary and probable arguments by considering the type of entitlement that the warrant 
provides for drawing the conclusion. When the warrant entitles us to draw the conclusion "unequivocally", the argument is necessary, i.e., it is an argument whose conclusion is to be claimed "necessarily". But when "the warrant just entitles us to draw our conclusion only tentatively (qualifying it with a 'probably'), subject to possible exceptions ('presumably'), or conditionally ('provided that...')" (1958: 148), then the argument is only probable. According to this, it would not be the form of the argument but the nature of the case at stake that determines which arguments are necessary or probable. Conclusions drawn necessarily because of warrants which are physically, morally, practically, mathematically, etc., necessary will happen to be as conclusive as those drawn from warrants which are formally necessary. That is, necessary arguments would just depend on warrants stating formal, conceptual, physical, moral, practical, mathematical, etc., necessities. And both necessary and probable arguments may be valid in Toulmin's sense.

The second distinction is that between formally and nonformally valid arguments. Toulmin says that a formally valid argument is an argument "set out in such a way that its conclusion can be obtained by appropriate shuffling of the terms in the data and warrant" (1958: 148). But this definition would have as a consequence that an invalid argument like "No horses are humans; No humans are four-legged; So no horses are four-legged" would be formally valid, because its conclusion can be arrived at by shuffling the parts of the premisses and rearranging them in a new pattern $^{6}$. Thus, even though in the final sections, I am going to criticise the idea of "formal truths", let me introduce the following alternative definition: a formally valid argument would be an argument whose warrant is formally true, or in other words, an argument whose warrant is a claim that it is true for "formal" reasons, i.e., because of the meanings of the logical terms involved. Thus, whereas the argument "Socrates is human, therefore, he is mortal" is a non-formally valid argument (its warrant being the "biological" truth "if Socrates is human, then he is mortal"), the argument "Socrates is human, and every human is mortal, therefore, Socrates is mortal" is a formally valid argument (its warrant being the formally true claim "if Socrates is human and every human is mortal, then Socrates is mortal”). Formal systems of inductive logic would also try to determine this type of

\footnotetext{
${ }^{6}$ I owe this observation to one of the referees of this paper. Toulmin might answer that the consequence of that argument cannot really "be obtained by appropriate shuffling of the terms in the data and warrant". But in that case, he should give further explanations of what "appropriate shuffling" consists of, and it is doubtful that he might do it without already adopting certain formal criteria of argument validity.
} 


\section{Lillian Bermejo Luque}

"validity" for probable arguments, if only, in Toulmin's view, by distorting the real meaning of qualifiers like "probable" (1958: 153, 160).

Finally, there is the distinction between analytic and substantial arguments. On Toulmin's account, an argument is analytic if and only if "checking the backing of the warrant involves ipso facto checking the truth or falsity of the conclusion" (1958: 133, 140). Toulmin says that the distinction between analytic and substantial arguments is "the key distinction" of his account (1958: 234). And, not surprisingly, it is the one that received the strongest criticisms. I would like to propose the following characterization in order to try to avoid its problems: an analytic argument would be an argument whose warrant is an analytic truth. Toulmin says that "where an analytic argument leads to a tentative conclusion, we cannot strictly say any longer that the conclusion follows 'necessarily' - only, that it follows analytically" (1958: 141). Thus, on his account, not all analytic arguments are necessary. But on our account, as long as analytic truths are necessary, all analytic arguments will be necessary ${ }^{7}$. Yet, our definition would agree with Toulmin's that not all necessary arguments are analytic: "in other fields also a time comes when we have produced in support of our conclusions data and warrants full and strong enough, in the context, for further investigation to be unnecessary - so in this sense non-analytic arguments also can be conclusive” (1958: 234).

\section{Criticisms from formal logic}

Up to a point, the project of The Uses of Argument was rather contentious. Toulmin sought to promote an alternative to the traditional conception of logic, and with it, a renewal of Logic, a discipline that had already achieved a great success by his time. Formal theories tried to characterize the validity of everyday arguments by formal criteria. But in Toulmin's view, formally valid arguments are far from representative of the sort of everyday arguments by means of which we justify our claims and beliefs (1958: 124). Thus, if Logic has to enable us to determine which

\footnotetext{
${ }^{7}$ If we assume Quine's thesis that the only type of analytic propositions are logical ones, we may come to believe that the only possible type of analytic arguments are formal ones, as defined above-more precisely, formal, first-order classical arguments, in Quine's view. But this is neither Toulmin's, nor my view: formally valid and analytic arguments are not co-extensive in my view because "formal" truths are a sub-set of "analytic" truths: an argument like "this is red, therefore it is coloured" is analytic but not formally valid.
} 
everyday arguments are good or bad, the formal approach is to be abandoned.

Just a few years after the publication of The Uses of Argument, most reviewers coincided in pointing out that the real scope of Toulmin's theses amounted to a "revolution" for Logic ${ }^{8}$. Yet, they also agreed that his attempt was flawed. On the one hand, they complained that Toulmin's characterization of Logic was too constrained to syllogistic, which is indeed a poor representation of contemporary developments. On the other hand, this restriction was seen as an attempt at making sense of the elements of the syllogism in terms of their functions in arguments. But according to Manicas (1966) and Castañeda (1960), Toulmin's characterization of two of the key elements of his model of argument (the backing and the warrant) is not based on different logical functions within arguments, but rather on different grammatical characterizations, namely, backings as categorical statements of fact, and warrants as conditional, hypothetical statements. Contrary to Toulmin, Castañeda argued that there is no good reason to distinguish warrants and backings from major premises. After all, both ways of phrasing an argument - that is, "Reason, Warrant, so Claim", and "Reason, Backing, so Claim"-result in analytic arguments, and these are arguments that do not seem to be in need of being completed or rephrased in any way in order to "show the sources of their validity".

In addition, it may be argued that Toulmin's criticism that formal theories are not concerned with the strength of the arguments we employ in everyday reasoning and conversation is misleading. Formal theories would be exclusively concerned with the validity of our inferences, whereas the value of an argument, understood in terms of the strength that it confers to its conclusion, would be a matter not only of the validity of its inference, but also of the truth of its premises. Certainly, formal theories could not deal with the appraisal of arguments as means to support the claims for which we argue, but just because they are a means to decide on validity, not to decide on truth. In this respect, Toulmin's conception of Logic would seem to point at erasing the distinction between validity, a property of inferences, and truth, a property of the claims for which we $\operatorname{argue}^{9}$. But, whereas the determination of

8 For example J. C. Cooley (1959), C. L Hardin (1959), H. N. Castañeda (1960), or P. T. Manicas (1966).

${ }^{9}$ As one of my referee notices, most authors take Toulmin's conception of Logic as focusing on fields as providers of standards to evaluate inferences. According to this view, he would still preserve the distinction between Logic and Epistemology. However, in Bermejo-Luque (2006) I have argued against this view of fields as providers of standards rather 


\section{Lillian Bermejo Luque}

truth involves all our knowledge of the world and is far from being a straightforward task, the determination of (formal) validity would be a reachable result. Furthermore, it would be an important step, as it would warrant truth-preservation. And if it is true that warrants have the same logical function as major premises, then there would not seem to be any gain in Toulmin's proposal. As Castañeda puts it:

[I]t is not obvious how such contrast is better than the customary way of putting the matter: either you criticize the argument because it is not formally valid or because it has at least one false premise. (Castañeda, 1960: 292)

I think that these observations show that it is necessary to distinguish between Toulmin's criticism of formal validity as a criterion of argument goodness, and his conception of logic as essentially informal. This puzzle is indeed at stake in The Uses of Argument. For Toulmin frequently says, for example, that Logic should be seen as a discipline providing the "standards of achievement which a man, in arguing, can come up to or fall short of, and by which his arguments can be judged” (1958: 8). He considers that Logic is "concerned with the soundness of the claims we make" (1958:7), rather than with the task of telling valid from invalid inferences, and he says that this requires more than mere calculations, it requires "experience, insight and judgment” (1958: 188). In that sense, I think it was a mistake on Toulmin's side to conceive of Logic as (normative) Argument Theory rather than as (normative) Inference Theory. As he argues, formal validity is not equivalent to argument goodness, indeed; but the truth is that it was not meant to be so; rather, it was meant to be equivalent just to inference goodness.

However, I think Toulmin was right in criticizing both traditional logicians' formal approach to Logic and traditional epistemologists' assumption that the normativity of arguments is, at least in part, a formal matter. The rest of this paper is devoted to a defense of these Toulminian ideas, which I take to be crucial insights regarding the normative study of argumentation-on the one hand, because most of us think of argumentation as constituted by, among others, by logical properties; and on the other hand, because a suitable theory of argumentation should constitute an alternative to traditional epistemology in dealing with the concept of justification, i.e., the sort of property that good argumentation confers on the claims and beliefs for which we afford reasons.

than as providers of reasons, warrants and backings, i.e., as branches of knowledge consisting of claims put forward with different qualifiers. A normative discipline for fields, so conceived, would rather be a discipline about the credentials of any claim, i.e., a form of Epistemology. 


\section{Logic as non-formal normative inference theory}

As Toulmin says, formal logicians would have made validity judgments dependent on our ability to determine consistency/inconsistency relationships among propositions. Yet, to determine this type of relationship is essentially dependent on the way we express the propositions involved. In that sense, the requirement of formalizing natural language argumentationconsisting of statements, not of propositions (1958:180) —would not be just a mere commitment with generality by formal theories, but also a crucial step to determine this type of relationship: it is due to the interpretation of our statements and their formalization that they become available.

By formalizing our statements, consistency relationships can be a priori determined by inference rules and axioms that may be interpreted in a merely syntactic way. Yet, their effectiveness in sanctioning the adequacy of the corresponding inferences depends on their suitability to endorse our intuitions respecting certain "formal" truths. That is, they are meant to endorse the meaning of the logical vocabulary that is supposed to be at stake in natural language arguments, given the sort of formalizations that the particular formal system allows ${ }^{10}$. This is the vocabulary that would sanction the corresponding rules, and that would determine whether a set of propositions is finally consistent or not. Consequently, when we depict a natural language argument in formal terms we commit ourselves not only to a given interpretation of the statements constituting it, but also to an interpretation of the inferential relationships among its alleged propositions. Thus, if we assume that validity/invalidity is a matter of logical form, the possibilities that a particular formal system allow for formalizing our statements will happen to play a crucial role in argument evaluation.

On the other hand, according to the formal approach to Logic, a natural-language argument is valid if it has a valid logical form and invalid if it has no valid logical form. But, as Gerald Massey argued in "Are There Any Good Arguments That Bad Arguments Are Bad?" (1975), because of this asymmetry, in order to establish that an argument is invalid, we should be able to establish that there is no (real or possible) formalization of this argument that happens to be a formally valid argument within any (real or possible) formal system. Thus, if our formal systems are unable to determine that a

10 Either directly, as in the case of natural deduction systems, or indirectly, as in the case of calculi based on axioms and transformation rules. 


\section{Lillian Bermejo Luque}

given argument is valid, then, following the standard conception of validity as formal validity, we could not say that it is invalid either.

Finally, the fact that there are alternative systems of logic would also seem to put in trouble the view that inference validity is a matter of form: after all, which form should prevail in our appraisal, the one according to which the argument is valid, or the one according to which it is not? To determine that a natural language argument $a$ is valid is to say that, given our interpretation of the statements involved, given our formalization of the corresponding propositions, and given our logical intuitions for accepting the particular model according to which $a$ is valid, $a$ is valid.

In the light of these difficulties, we might rather think of the formal approach to Logic as the project of using formal systems merely as an instrument for inference evaluation. On this account, the concept of argument validity would be different from the concept of formal validity, and the relationship between formal validity/invalidity and natural language validity/invalidity would not seem to be sufficiently connected so as simply to pass along to formal theories the question of the validity of natural language arguments in general.

Actually, this is, in a way, Toulmin's view. Toulmin considers that the reasons why an argument is valid "are to be understood only when we turn to consider the backing of the warrant invoked" (1958: 143). As he sees it, that which would be wrong with the traditional view is the idea that, in order to entitle the drawing of a conclusion 'necessarily', inference rules have to be exclusively formal, that is, rules endorsing the meaning of the logical terms involved. As Toulmin points out in characterizing his concept of warrant, the warrants of non-formally valid arguments are as legitimate inference rules as is modus ponens. And many warrants, not only formal ones, even entitle us to drawn conclusions 'necessarily', for example, those stating conceptual truths like "if it is red, then it is colored"; or moral truths like "if, by doing that, you unnecessarily hurt someone, you should not do it”; or, if your metaphysical convictions, like Toulmin's, do not preclude them, warrants stating physical necessities like "if the experiment is supposed to reduce entropy in a close system, then it is wrong” or even, "if it is a hundred tons, then you won't lift it single-handed" (1958: 27); or legal necessities like "if she is the defendant's wife, then you cannot oblige her to testify"; etc.

On this account, there would be a non-formal concept of validity whose characterization is the goal of Logic as a normative theory of inference. It would be by reference to it that formal logicians try to develop new models able to show that valid 
arguments are formally valid, i.e., valid by "formal" criteria. Yet, I am going to argue, formal criteria are but a type of substantial criteria. Moreover, the non-formal concept of validity is also nonanalytic, but pragmatic. It is not a matter of meanings, but of the constitutive conditions in which inferences supervene, namely, the acts of reasoning and arguing. In my view, this is the strongest, yet half-developed, thesis of The Uses of Argument.

\section{Analitic validity and argument goodness}

According to Toulmin, "so far as formal logicians claim to say anything of relevance to arguments of other than analytic sorts, judgement must therefore be pronounced against them: for the study of other types of argument fresh categories are needed, and current distinctions (...) must be set on side” (1958:147). Yet, he also says that "provided that the correct warrant is employed, any argument can be expressed in the form 'Data; warrant; so conclusion' and so become formally valid" (1958: 119). Thus, given that all formally valid arguments are analytic, Toulmin would seem to agree that formal systems are suitable for determining any type of validity, and his only reason for criticizing the formal approach to Logic would be that, for some arguments, we can determine validity by other means. As we have seen, this is Castañeda's overall criticism of Toulmin's position. On the contrary, in this section, I am going to argue that Toulmin has very good reasons to defend a conception of validity that is irreducibly substantial. My final goal will be to argue for the view that, in the last resort, analytic validity is a species of it.

In Castañeda’s view,

[I]t may not be amiss to point out that the fundamental difference between Toulmin and ordinary logicians is actually never taken up by Toulmin — viz. that or whether it is a mistake to claim that many of our arguments (...) are enthymematic. In fact, his granting that every argument requires a warrant and that this warrant may be always made explicit (e.g., 128, 118, 135) prevents Toulmin from differentiating himself from ordinary logicians. (Castañeda, 1960: 289)

That is, treating formal systems as standards for argument validity would require treating many of them as enthymemes. Enthymemes are incomplete arguments that a proper analysis should fully depict. Following this strategy for argument evaluation, we should incorporate the corresponding warrants of these arguments as premises, so that they result in formally valid arguments, i.e., instances of a modus ponens argument type, according to our 


\section{Lillian Bermejo Luque}

proposed characterization of warrants. But, is it right to phrase everyday argumentative discourse and reasoning this way, so as to try to accomplish formal systems' standards for inferences?

If, as Toulmin says, "surely we cannot get from any set of data to a conclusion without some warrant" (1958: 128), then any argument has a warrant. Thus, an argument whose warrant has been incorporated as a premise will have a new warrant that will be an instance of the modus ponens inference rule, whereas the original argument's warrant may have nothing to do with formal truths, having its own source of legitimacy, a different kind of authority and, above all, a different meaning and import. Consequently, formal logicians' pretension of portraying the logical structure of everyday substantial arguments by completing and formalizing them in this way would happen to be a plain misinterpretation of the original arguments.

Following a well known argument by Lewis Carroll (1895), Wayne Grennan (1997) has shown that warrants-or 'inference claims' as he calls them-are necessarily implicit in arguments because they cannot be incorporated to it without changing the meaning of the former argument:

[C]onsider an argument utterance symbolized as "A, so B". By definition, the inference claim is "if A then B". Now suppose we add "if A then B" to the original argument, in an attempt to make the inference claim explicit. The argument form is now " $A$, if $A$ then $B$; so $B$ ". But the inference claim for the revised argument is "if $A$, and if $A$ then $B$, then $B$ ". If we now add this, we change the stated argument again, generating a new inference claim. Thus, an infinite regress begins when we try to make it explicit in the argument. (Grennan, 1997:

Thus, contrary to what Toulmin seems to say (see for example 1958: 119), the main reason to abandon the formal approach, in general, is that the warrant of an argument can never be incorporated as a premise. As Grennan shows, if we try to do it, we generate a new, different argument, with a new, different warrant. According to this view, that which makes valid and conclusive arguments like "the position of the Sun, Moon, Earth are..., therefore, there will necessarily be a partial eclipse of the Moon” is the fact that the truth of its conclusion follows necessarily from the truth of its premises. And why does this happen? Is it because this argument can be interpreted as an instance of formally valid argument schema? Surely it can, namely, by treating it as an enthymeme. As Castañeda says, 
[P]atently, similar considerations apply to (that argument), whose major premise, the ordinary logician would emphasize, "is a complicated one involving a good deal of astronomical theory; its enthymematic character should not make us lose sight of the logical character of the term 'necessarily', nor should it make us oblivious to the distinction between (this argument) and the complex arguments leading to that implicit major premise. I am the last person”, he would continue, "to deny the hypotheticodeductive nature of scientific research as well as of detective or intelligence work. Of course, Sherlock Holmes and scientists make deductions from data, as you have justly iterated, Professor Toulmin (121, 137f.), but also from implicit assumptions-which you wish to call warrants. (Castañeda, 1960: 288)

However, this strategy amounts to saying that the argument is not valid as it stands, but only when "completed" with that "good deal of astronomical theory". On the contrary, on our account, the argument is conclusive and valid because its warrant is necessarily true, and all that good deal of astronomical theory only serves to let us know that the argument is valid indeed. Also, on this account, valid arguments are arguments whose warrants are sound, in the sense that they entitle us to put forward our conclusion with the qualifier with which we have actually put it forward. After all, a warrant is a claim that states that if the reason is true, the conclusion is true; therefore, if this claim is true if the reason is true, the conclusion has to be true. Likewise, if the warrant of our argument is probable/necessary, then, if the reason is true, then probably/necessarily the conclusion will be true-and so on for other qualifiers.

As the constitutive elements of inferring that they are, warrants are not "rules of inference" in the sense of "guaranties for a safe inferring", but the explicitation of the very inference that we make in affording a reason for a conclusion. It is because others attribute to us this implicit claim or belief that our act of believing or of saying that $p$ and then coming to believe or say that $q$ counts for them as an act of reasoning or an act of arguing. Thus, invalid arguments would also have warrants: they are the alleged links between reasons and claims that the reasoner/arguer implicitly appeals to. But they are not sound: they do not really entitle the arguer to draw the conclusion with the force he has actually drawn it. And, of course, formally valid arguments would have warrants too.

In this respect, I think that Castañeda's criticism that warrants and backings do not play different functions because both "Reason, 
Warrant, so Claim" and "Reason, Backing, so Claim” are analytic arguments misses the point. If we accept that in order to turn a claim into a reason we need a link between this reason and the conclusion for which this claim would be a reason, then whenever we have an argument we will have a link which is not part of the reasons but the link between them and the conclusion. In this sense, the warrant of an argument always remains implicit; it cannot be part of the premises.

Toulmin himself says that warrants are implicit (1958:100). But sometimes, he seems to consider the possibility of incorporating the warrant as part of the premises. In my view, there is no incoherence here. Certainly, we can take the content of the warrant as an additional premise. But then we are just turning the original argument, whose warrant was "if $\mathrm{R}$, then C", into an analytic, new, argument whose warrant is "if $\mathrm{R}$ and $\mathrm{W}$, then C". This new warrant does not state the relevant relation between $\mathrm{R}$ and $\mathrm{C}$ that $\mathrm{W}$ stated, but a formal relation between $\mathrm{R} \& \mathrm{~W}$ and $\mathrm{C}$. Noticeably, Toulmin was using this example in order to show that any argument may be turned into a formally valid one just by adding as a premise (the content of) the warrant (1958:119). And this is exactly our definition of a formally valid argument: an argument whose warrant is true for formal reasons-as happens with an instance of Modus Ponens.

\section{Conclusion}

As we have seen, formal criteria are, in general, neither sufficient nor necessary conditions for validity, soundness or justification. They are not necessary because, as we have seen, what makes an argument like "She is the defendant's wife, therefore, you cannot oblige her to testify" valid is the warrant "if she is the defendant's wife, then you cannot oblige her to testify", which is actually true $^{11}$. A formal logician may argue that it is valid because it is enthymematic, but we have seen that there are good reasons against treating substantial arguments as enthymematic. Actually, formal criteria would not be sufficient for inference validity either, precisely because many invalid arguments may be turned into formally valid ones by treating them as enthymemes; and in that

${ }^{11}$ Following Toulmin's analysis of 'cannot', it is easy to see that this warrant is a statement with true conditions. Namely, those of a claim like "national laws being as they are, you cannot oblige a defendant's wife to testify. That would be a violation of such and such law and it would amount to losing the case”. 
case, what should we want formal validity for? In Castañeda's view, the answer would be something like "by doing so, we can criticise the argument for having a false premise”.

In this final section, I would like to criticise the very idea of “formal” criteria. Robert Brandom has offered an argument along these lines against the formalist conception of logic as normative for inference. Recalling Sellars's concept of material inference and his criticism of "the received dogma ... that the inference which finds its expression in 'It is raining, therefore the streets will be wet' is an enthymeme” (Brandom, 2000: 53), Brandom shows that, in point of fact, formally valid inferences are particular cases of materially valid ones. As far as we privilege a subset of vocabulary, the goodness of an inference is indeed a matter of form, but this just means that "it is a materially good inference, and it cannot be turned into a materially bad one by substituting non-privileged vocabulary for non-privileged vocabulary in its premises and conclusions” (Brandom, 2000: 55). Like Toulmin, Brandom points out that the concept of formal validity is essentially dependent on the possibility of privileging a particular set of expressions that would allow for the use of certain inference rules as a matter of "logical form". Thus, there would be nothing like the intrinsic "logical form" of a discourse, apart from the set of vocabulary that we decide to privilege in a particular occasion by offering the rules that are supposed to sanction the use of these expressions and, consequently, the inferences that we are entitled to make from the propositions containing them.

If we adopt the formal approach to Logic, its normativity would be a matter of the particular way we convey the meaning of a particular set of expressions. But in point of fact, this is weakly normative. Unless we could settle once and for all a set of rules conveying the meaning of a particular set of vocabulary, the question will always remain open whether we should adopt another interpretation of this vocabulary, or even another set of vocabulary, in order to evaluate particular inferences according to formal criteria. Thus, the problem of conceiving of Logic as a set of formal theories resulting from conveying the meaning of certain sets of privileged vocabulary is that it impedes the possibility of conceiving of Logic as fully normative for those activities in which inferences supervene, namely, reasoning and arguing. On the contrary, on the pragmatist account that we endorse, the normativity of Logic would be a matter of its ability to determine what counts as an inference at all, whereas the logical evaluation of a piece of reasoning or arguing -given the particular logical theory defended here- would be a matter of our ability to determine which qualifiers correspond to the reasons and warrants employed in it. 


\section{Lillian Bermejo Luque}

Toulmin considers that the criteria that determine the use of qualifiers, including the qualifier 'necessarily', are field-dependent. In this sense, we may take him to believe, like Brandom, that every argument is, in point of fact, substantial. Even analytic and formal arguments have warrants whose standards are not merely syntactic, but "substantive", in the sense of endorsing the truths constituting a certain field. These warrants would bear the meaning of the privileged vocabulary constituting the basis of a particular formal system. Evidence of the "substantiveness" of formal warrants is the fact that there are alternative systems representing different views of, for example, what we are entitled to infer from double negation, or whether excluded middle is unrestrictedly acceptable. According to this evidence, the idea that formal validity is especially valuable as a means to preserve truth is a chimera. In the last resort, any deduction, defined as an inference in which, if the premises are true, the conclusion necessarily is true, leaves open the question, "What does 'necessarily' mean here?" As far as there are alternative systems, these rules cannot be said to be "self-evident", for example, but rather, constitutive of a particular system. Thus, for a formal logician, the only answer would be something like "inference rules in this system are so". But this answer is adequate just to the question of the correctness of a particular inference regarding the standards of the system from which it is appraised; it is not fine regarding the question of the adequacy of these very standards. Thus, a conception of logic as formal would face the problem of justifying its standards as standards for justification, a problem that becomes unsolvable if we really adopt them as standards for argument goodness and justification.

Contrastingly, the logical standards that underlie Toulmin's proposal would endorse a sort of necessity which is different from the necessity sanctioned by any formal system, standards that are pragmatically rather than semantically motivated. That is to say, they do not involve an appeal to alleged formal truths warranting the validity of those arguments that take them as their warrants, but to the constitutive conditions that determine that certain acts count as inferences - either the inferences proposed in giving reasons for a claim, or the inferences drawn in reasoning. The logic of an argumentative discourse or piece of reasoning would be the structure of the inferences that it endorses; and the correctness of this structure would be a matter of the correctness of its elements, namely, of the correctness of the corresponding statements playing as reasons, conclusions and warrants. 


\section{Acknowledgements}

I wish to thank Prof. Luis Vega and Prof. Javier Rodríguez Alcázar for their insightful comments and suggestions on an earlier version of this paper. Also, Prof. David Hitchcock has helped me to improve some of the views presented in this paper through a variety of fruitful discussions. And Prof. Anthony Blair has done a great editing job. Finally, the criticisms and suggestions of the anonymous reviewers of this paper have been just decisive. I would like to thank, specially, one of them for his detailed and insightful work with my paper.

The work presented here has been financed by a Juan de la Cierva Research Fellowship by the Spanish Ministry of Education and Science.

\section{References}

Bermejo Luque, L. (2006). “Toulmin’s Model of Argument and the Question of Relativism,” in D. Hitchcock and B. Verheij (Eds.), Arguing on the Toulmin Model: New Essays in Argument Analysis and Evaluation, pp 71-87. Dordrecht: Kluwer Academic Publishers.

Bermejo Luque, L. (2007). "Response to Hitchcock," in H.V. Hansen, C.W. Tindale, J.A. Blair, R.H. Johnson and D.M. Godden (Eds.), Dissensus and the Search for Common Ground. Windsor, ON: OSSA (CD Rom).

Brandom, R.B. (1994). Making It Explicit: Reasoning, Representing and Discoursive Commitment. Cambridge, MA: Harvard University Press.

Brandom, R.B. (2000). Articulating Reasons. An Introduction to Inferentialism. Cambridge, MA: Harvard University Press.

Castañeda, H. N. (1960). “On a Proposed Revolution in Logic.” Philosophy of Science, 27: 279-292

Carroll, L. (1895). "What the Tortoise said to Achilles.” Mind 4, 278-280.

Cooley, J.C. (1959). “On Mr. Toulmin’s Revolution in Logic.” Journal of Philosophy, 56: 297-319.

Grennan, W. (1997). Informal Logic: Issues and Techniques. Montreal: McGill-Queen's University Press.

Hansen H.V. \& R.C. Pinto (Eds.). (1995). Fallacies: Classical and Contemporary Readings. University Park, PA: The Pennsylvania State University Press.

Hardin, C.L. (1959). "The Uses of Argument”, in Philosophy of Science, 26, 319-320.

Hitchcock, D. (1998). 'Does the Traditional Treatment of Enthymemes Rest on a Mistake?', Argumentation,12, 15-37. 
334 Lillian Bermejo Luque

Hitchcock, D. (2007). “So,” in H.V. Hansen, C.W. Tindale, J.A. Blair, R.H. Johnson and D.M. Godden (Eds.), Dissensus and the Search for Common Ground. Windsor, ON: OSSA (CD Rom).

Manicas, P. (1969). “On Toulmin's Contribution to Logic and Argumentation." Journal of the American Forensic Association, 6: 111.

Massey, G. (1975). "Are There Good Arguments that Bad Arguments Are Bad." Philosophy in Context, 4, 61-77. Reprinted in H.V. Hansen \& R.C Pinto (1995).

Sellars, W. (1953). "Inference and Meaning." Mind, 62: 313-38.

Toulmin, S.E. (1958). The Uses of Argument. Cambridge: Cambridge University Press,. 